\title{
Construction of enhanced transcriptional activators for improving cellulase production in Trichoderma reesei RUT C30
}

\author{
Jiajia Zhang ${ }^{1}$, Chuan Wu' ${ }^{1}$ Wei Wang ${ }^{2}$, Wei Wang ${ }^{1 *}$ (ID and Dongzhi Wei ${ }^{1 *}$
}

\begin{abstract}
Enhancing cellulase production in Trichoderma reesei is of great interest for an economical biorefinery. Artificial transcription factors are a potentially powerful molecular strategy for improving cellulase production in T. reesei. In this study, enhanced transcriptional activators XYR1VP, ACE2VP, and ACE1VP were constructed by linking the $C$ terminus of XYR1, ACE2, or ACE1 with an activation domain of herpes simplex virus protein VP16. T. reesei transformants $T_{X Y R 1 V P \text {, }}$ $T_{\text {ACE2VP, }}$ and $T_{\text {ACE1VP }}$ showed improved cellulase and/or xylanase production. $T_{\text {XYRIVP }}$ has a cellulase-free phenotype but with significantly elevated xylanase production. Xylanase I and xylanase II activities [U/(mg biomass)] increased by $51 \%$ and $80 \%$, respectively, in $\mathrm{T}_{\text {XYRIVP }}$ in comparison with parental strain RUT C30. The filter paper activity of $\mathrm{T}_{\text {ACE2VP }}$ in the Avicel-based medium increased by 52\% compared to that of RUT C30. In the Avicel-based medium, $T_{\text {ACEIVP }}$ manifested an 80\% increase in FPase activity and a 50\% increase in xylanase activity as compared to those of RUT C30. Additionally, when pretreated corn stover was hydrolyzed, crude enzymes produced from $\mathrm{T}_{\text {ACE1VP }}$ yielded a greater glucose release than did the enzymes produced by parental strain RUT C30.
\end{abstract}

Keywords: Enhanced transcriptional activator, Trichoderma reesei, Transcription factor, Cellulase, XYR1, ACE2, ACE1

\section{Background}

Production of environment-friendly biofuels and chemicals from lignocellulosic biomass, which forms the skeleton of all plant cells, has received extensive attention (Hahn-Hagerdal et al. 2006). The conversion of lignocellulosic biomass into monosaccharides using cellulase is a critical step in the biorefinery process (Parisutham et al. 2014). The enhancement of cellulase production greatly reduces the cost of a biorefinery of lignocellulosic biomass (Vicari et al. 2012; Biddy et al. 2016).

Trichoderma reesei, an excellent secretor of enzymes, has been widely used for the industrial production of cellulase (Bischof et al. 2016). T. reesei produces three types of cellulases: cellobiohydrolases ( $\mathrm{CBH} 1$ and $\mathrm{CBH} 2)$, endoglucanases (mainly include EGL1 and EGL2), and $\beta$-glucosidase (mainly BGL1). Cellobiohydrolases and

\footnotetext{
*Correspondence: wadexp@ecust.edu.cn; dzhwei@ecust.edu.cn ${ }^{1}$ New World Institute of Biotechnology, State Key Lab of Bioreactor Engineering, East China University of Science and Technology, P.O.B. 311, 130 Meilong Road, Shanghai 200237, China

Full list of author information is available at the end of the article
}

endoglucanases synergistically hydrolyze cellulose to produce cello-oligosaccharides (mainly cellobiose). $\beta$-Glucosidases degrade cellobiose into the end product glucose. T. reesei also expresses large amounts of xylanase, among which XYN1 and XYN2 are the most abundant (Zeilinger et al. 1996). Strain RUT C30 serves as a cellulase hyperproducer and is employed in research and in the industry (Martinez et al. 2008; Bischof et al. 2016). Therefore, enhancing cellulase production in $T$. reese $i$ RUT C30 is useful for an economical biorefinery.

Cellulase production in T. reesei RUT C30 is transcriptionally coregulated by a set of transcription factors (TFs), including XYR1, ACE3, ACE2, and ACE1 (Mach-Aigner et al. 2008; Häkkinen et al. 2014; Bischof et al. 2016). Among them, XYR1 and ACE3 are key transcriptional activators, and deletion of $x y r 1$ or ace 3 abrogates cellulase production (Stricker et al. 2006; Akel et al. 2009; Häkkinen et al. 2014; Castro Santos et al. 2016). ACE2 also serves as a transcriptional activator of cellulase production, and deletion of ace 2 decreases mRNA levels of cellulase-encoding genes, 
such as cbh1, cbh2, egl1, and egl2 (Aro et al. 2001). ACE1 is recognized as a transcriptional repressor of cellulase production, and deletion of ace 1 increased the production of all main cellulase and xylanase in sophorose- and cellulose-induced cultures (Saloheimo et al. 2000; Aro et al. 2003; Portnoy et al. 2011).

Artificial TFs are a potentially powerful molecular strategy for modulating target gene expression and for obtaining an enhanced phenotype (Ju et al. 2008; Lee et al. 2013). Specific artificial transcriptional activators have been constructed to improve cellulase production in T. reesei (Su et al. 2009; Zhang et al. 2016a, 2017, 2018). An artificial transcriptional activator constructed by fusing the two DNA-binding domains of ACE1 and CRE1 with an effector domain of ACE2 can regulate the expression of cellulase genes ( $\mathrm{Su}$ et al. 2009). T. reesei U3, a mutant strain with enhanced cellulase production, was identified via screening with construction of an artificial zinc finger protein library (Zhang et al. 2016a). Similarly, transformant zxy-2 of an artificial transcriptional activator-containing the binding domain of CRE1 linked to the effector and binding domains of XYR1-yields constitutive cellulase production from glucose as the sole carbon source (Zhang et al. 2017). A universal and simple pattern strategy for constructing a series of artificial transcriptional activators in $T$. reesei must be developed further. Recently, we improved cellulase production in $T$. reesei by substituting natural TFs with minimal transcriptional activators (Zhang et al. 2018) designed by linking one DNA-binding domain of ACE2 or CRE1 to the $C$-terminal 78 amino acid residues (aa) of herpes simplex virus protein VP16, which act as an activation domain that activates transcription of early viral genes (Sadowski et al. 1988; Triezenberg et al. 1988).

Here, we developed three novel artificial transcriptional activators as enhanced transcriptional activators (ETAs)-XYR1VP, ACE2VP, and ACE1VP-in T. reesei RUT C30 via a universal and simple pattern strategy. These ETAs were constructed by fusing the strong transcriptional activation domain of VP16 to the $\mathrm{C}$ terminus of natural TFs (XYR1, ACE2, and ACE1) and transfected into hypercellulolytic strain T. reesei RUT C30 to replace the natural TFs (XYR1, ACE2, and ACE1, respectively) by homologous double exchange. Next, the effects of these ETAs on cellulase production were investigated. These ETAs were shown to improve cellulase production in $T$. reesei. Our study offers a novel strategy for obtaining high-yield cellulase $T$. reesei strains as well as provides insight into the regulatory mechanisms of action of TFs for cellulase production.

\section{Results and discussion}

\section{Construction of transformants with ETAs}

Enhancing the function of TFs to improve cellulase production in $T$. reesei is considered an effective strategy (Zhang et al. 2018). We hypothesized that cellulase production would be increased by fusing the strong transcriptional activation domain of VP16 to the $\mathrm{C}$ terminus of a natural TF to enhance its transcriptional activation. Three ETAs including XYR1VP, ACE2VP, and ACE1VP were designed by fusing the VP16 domain to the C terminus of XYR1, ACE2, and ACE1, respectively (Fig. 1). The expression plasmids pXYR1VP, pACE2VP, and pACE1VP for the three ETAs were constructed by ligating the erasable hygromycin selection marker LML2.1 (Fig. 1), which was eliminated by the product of a chimeric Cre recombinase gene (Zhang et al. 2016b). The expression plasmids were introduced into the genome of the $T$. reese $i$ hypercellulolytic mutant RUT C30 by Agrobacteriummediated transformation to replace natural TFs XYR1, ACE2, and ACE1 by homologous double exchange (Fig. 1), eliminating the risk of random insertion and unpredictable mutagenesis. The transformed strains with confirmed gene replacement were selected to eliminate the hygromycin selectable marker by xylose induction to obtain the final transformants. All the transformants were identified as correctly transformed ETA strains and harbored single-copy DNA integration (Additional file 1: Figure S1). Three randomly screened transformants $\mathrm{T}_{\mathrm{XYR} 1 \mathrm{VP}}-1 /-2 /-3, \mathrm{~T}_{\mathrm{ACE} 2 \mathrm{VP}}-1 /-2 /-3$, and $\mathrm{T}_{\mathrm{ACE} 1 \mathrm{VP}}-1 /-2 /-3$ for each ETA were analyzed further.

\section{Growth of the transformants expressing ETAs}

To determine whether the ETAs helped to increase cellulase production, we first examined the growth of the transformants using parental strain RUT C30 as a control. The growth of ETA transformants $\mathrm{T}_{\mathrm{XYR1VP}}$, $\mathrm{T}_{\mathrm{ACE} 2 \mathrm{VP}}$, and $\mathrm{T}_{\text {ACE1VP }}$ was investigated in the minimal medium (MM) containing glycerol, Avicel, or lactose as the sole carbon source (Fig. 2a-c). Regardless of the carbon sources, growth rates of transformants $T_{A C E 2 V P}$ and $\mathrm{T}_{\mathrm{ACE} 1 \mathrm{VP}}$ were not significantly different from that of the control (Fig. 2a-c). Thus, ACE2VP and ACE1VP had no effect on basic cellular metabolism. Similarly, the growth of $\mathrm{T}_{\mathrm{XYR} 1 \mathrm{VP}}$ showed no significant differences from the control when cultured in glycerol (Fig. 2a). Nevertheless, the growth rates of $\mathrm{T}_{\mathrm{XYR} 1 \mathrm{VP}}$ on lactose and Avicel were much lower than the growth rate of the control, with growth on Avicel being particularly slow (Fig. 2b, c), indicating that XYR1VP limits cellulase synthesis in $\mathrm{T}_{\mathrm{XYR} 1 \mathrm{VP}}$. 


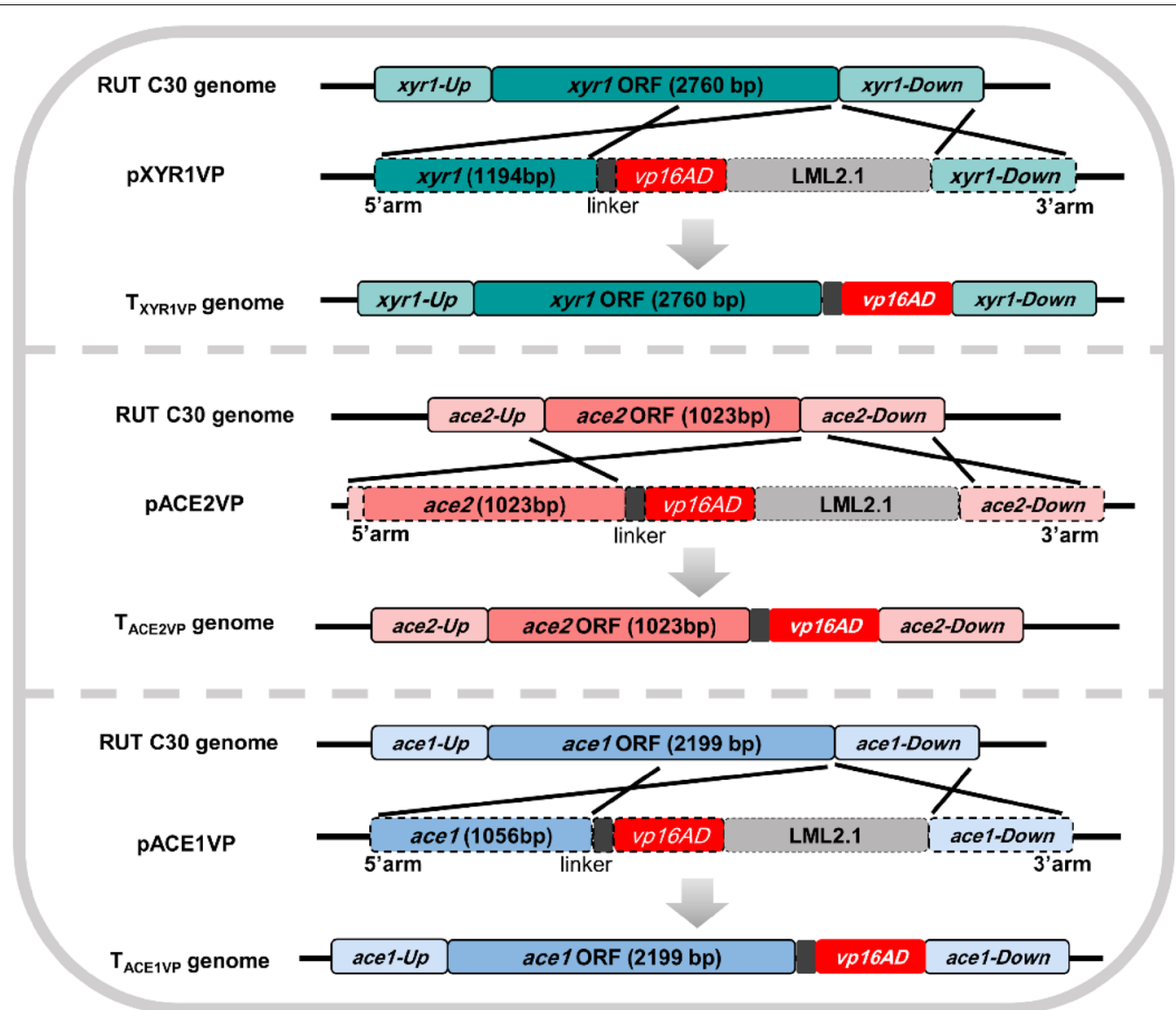

Fig. 1 Construction and transfection of the ETAs. A short flexible linker (GGGGSGGGGS) and activation domain of VP16 (vp 16AD) were fused with the $C$ terminus of the natural proteins, ACE2 (aa 1-341), ACE1 (aa 1-733), or XYR1 (aa 1-920). The C-terminal last encoding codon of each natural protein was fused to the linker and then fused to the activation domain of VP16 by Seamless Cloning and Assembly Kit (TransGen, Beijing, China). ETAs were used to replace the natural regulators in T. reesei RUT C30. Transformants $T_{A C E 2 V P,} T_{A C E 1 V P,}$ and $T_{\text {XYR1VP }}$ were obtained after xylose-induced marker rescue
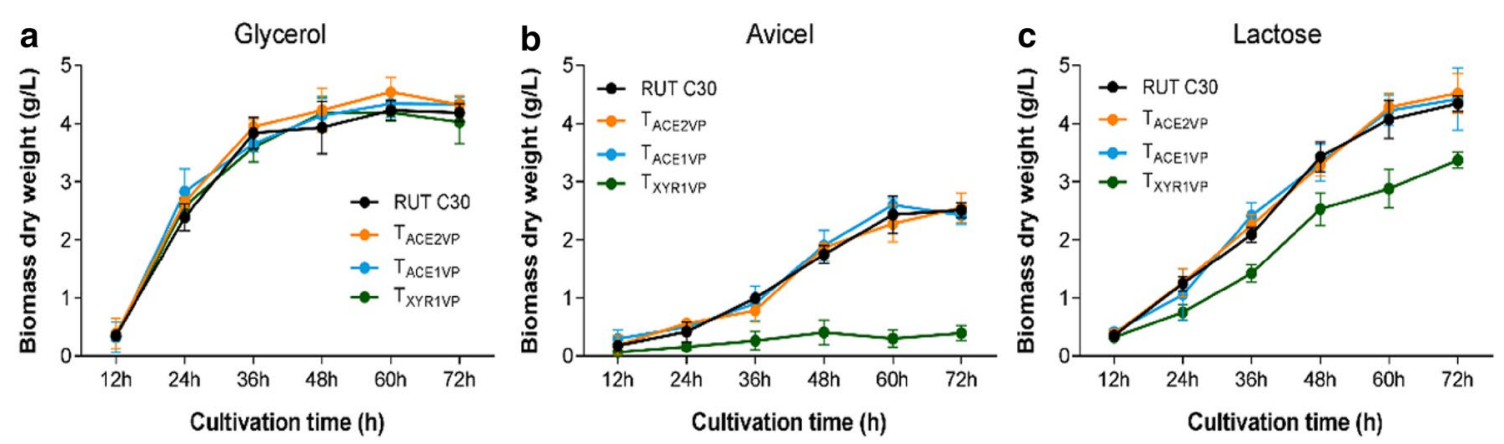

Fig. 2 Cell growth differences among $T_{\text {XYR1VP, }} T_{\text {ACE2VP, }}$ and $T_{\text {ACE1VP }}$ Cultured on glycerol (a), Avicel (b), and lactose (c). Error bars show the respective standard deviations of three biological replicates

\section{XYR1VP abrogated cellulase production}

To test whether XYR1VP decreases cellulase production, we determined the cellulase-related activities of $\mathrm{T}_{\mathrm{XYR} 1 \mathrm{VP}}$ under Avicel and lactose culture conditions.
$\mathrm{T}_{\text {XYR1VP }}$ manifested nearly no filter paper activity (FPA) in the Avicel- or lactose-based medium (Fig. 3A). Similarly, the $p$-nitrophenol-D-cellobioside hydrolase ( $p$ NPCase), the sodium salt of carboxymethyl cellulose 

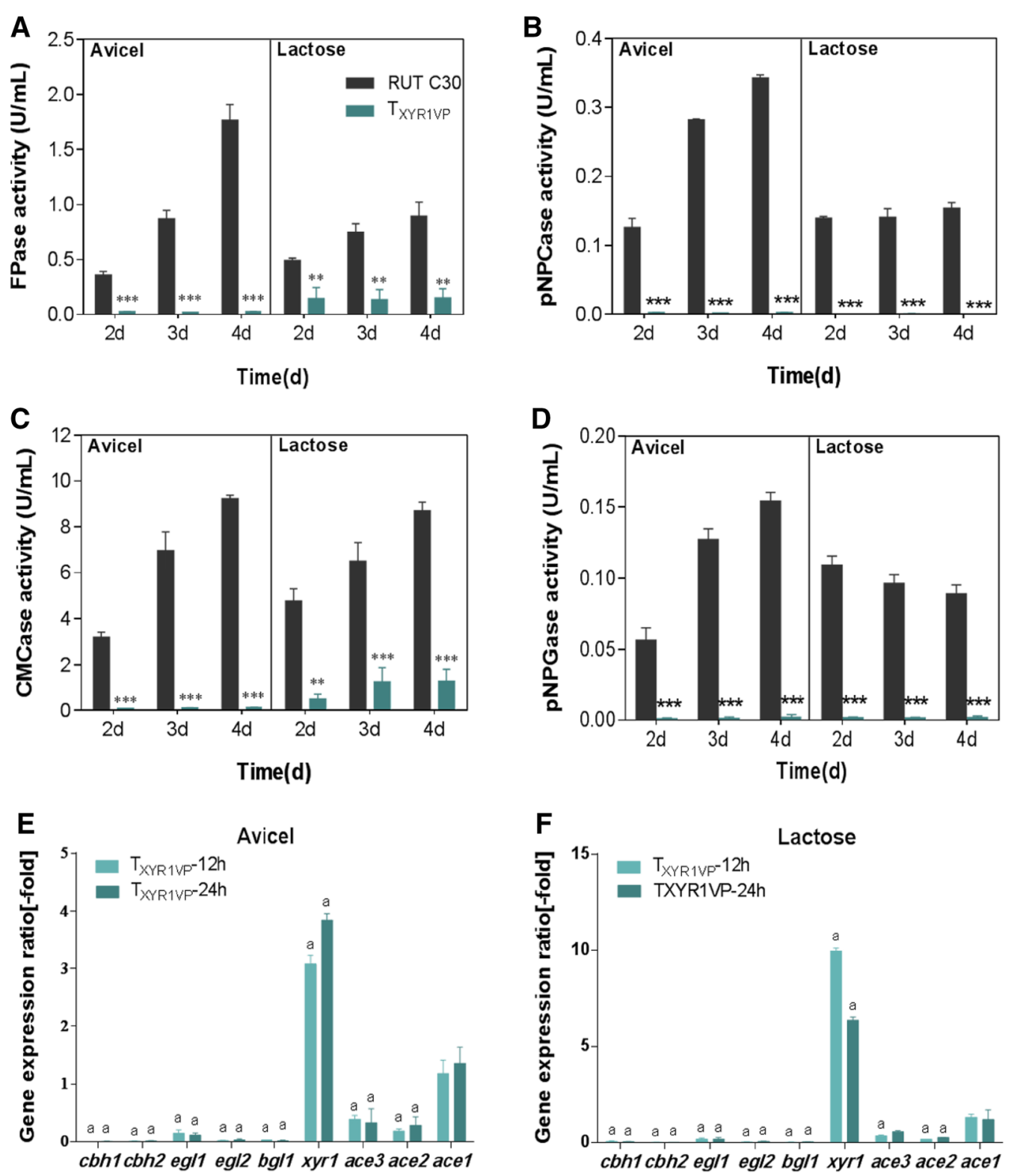

Fig. 3 Cellulase production and a comparison of transcript levels of cellulase-related genes between strains $T_{\text {XYRIVP }}$ and RUT C30. FPase (A), pNPCase (B), CMCase (C), and pNPGase (D) activities of RUT C30 and T XYRIVP after a switch from glycerol to $20 \mathrm{~g} / L$ Avicel or lactose. Enzymatic activities were measured at 2, 3, and 4 days after the transfer. Error bars show the respective standard deviations of three biological replicates; asterisks indicate significant differences ( $P \leq 0.05 ;{ }^{* *} P \leq 0.01 ;{ }^{* *} P \leq 0.001 ;$ n.s. not significant) between the transformants and RUT C 30 , as assessed by Student's $t$ test. Expression ratios of cellulase-related genes on $20 \mathrm{~g} / \mathrm{L}$ Avicel (E) or lactose (F) for 12 and $24 \mathrm{~h}$ after the switch from glycerol. Data on $T_{\text {XYRIVP }}$ transformants were normalized to the corresponding gene expression levels at the same time points in RUT C 30 . Values represent the mean of three biological replicates, and the error bars denote standard deviations. Gene expression ratios greater than twofold or less than 0.5-fold are marked with "a"

hydrolase (CMCase), and the 4-nitrophenyl-beta$\mathrm{D}$-galactopyranoside hydrolase ( $p$ NPGase) activities in $\mathrm{T}_{\mathrm{XYR} 1 \mathrm{VP}}$ were nearly absent as compared to the control (Fig. 3B-D). Additionally, the transcript levels of cellulase-related genes $c b h 1, c b h 2$, egl1, and egl2 were low compared to those in the control (Fig. 3E, F), suggesting that XYR1VP abrogated cellulase production. Consequently, the dramatically decreased growth rate of $\mathrm{T}_{\mathrm{XYR} 1 \mathrm{VP}}$ on Avicel resulted from its cellulase-negative phenotype in the presence of inducing carbon sources (Avicel and lactose). A lack of cellulase hindered the growth of $\mathrm{T}_{\mathrm{XYR} 1 \mathrm{VP}}$ in the Avicel-based medium. The 
cellulase-free phenotype was observed not only in XYR1VP transformants but also in ACE3VP transformants, in which the strong transcriptional activation domain of VP16 was fused to the C terminus of ACE3 (data not shown).

Of note, although cellulase production of $\mathrm{T}_{\mathrm{XYR} 1 \mathrm{VP}}$ in lactose- and Avicel-based media was abrogated, xylanase production of $\mathrm{T}_{\mathrm{XYR} 1 \mathrm{VP}}$ was unrepressed and even enhanced (Additional file 1: Figure S2a, b). $T_{\text {XYR1VP }}$ showed a xylanase upregulation phenotype in glyceroland lactose-based media, and a similar xylanase activity $(\mathrm{U} / \mathrm{mL})$ was observed in the Avicel-based medium as compared to that in the control. Additionally, $\mathrm{T}_{\mathrm{XYR} 1 \mathrm{VP}}$ showed higher xylanase activities per unit of biomass with a $51 \%$ increase in xylanase I activity and an $80 \%$ increase in xylanase II activity compared to that in RUT C30 (Additional file 1: Figure S2a, b). Elevated transcript levels of xylanase genes were detected in $\mathrm{T}_{\mathrm{XYR} 1 \mathrm{VP}}$ regardless of the carbon sources; this finding is consistent with the enhanced xylanase activities (Additional file 1: Figure $\mathrm{S} 2 \mathrm{c}-\mathrm{e}) . \mathrm{T}_{\mathrm{XYR} 1 \mathrm{PP}}$, a xylanase-hyperproducing strain with a cellulase-free phenotype, can be employed in some industries where xylanase is desired, while cellulase is undesirable, e.g., in paper recycling (Buchert et al. 1998).

The transcript levels of TFs $x y r 1$, ace 3 , ace 2, and ace 1 in $\mathrm{T}_{\mathrm{XYR} 1 \mathrm{VP}}$ were also analyzed. As shown in Fig. 3E, F, ace3 and ace 2 transcript levels were lower in $\mathrm{T}_{\mathrm{XYR} 1 \mathrm{VP}}$ than in the control (the gene expression ratio was less than 0.5 -fold). The transcript levels of the xyr 1 domain were higher than those of the control (the expression ratio was more than threefold) and the transcript levels of ace 1 had no significant differences from those of RUT C30, which cannot explain the cellulase-negative and xylanase overexpression phenotypes of $\mathrm{T}_{\mathrm{XYR} 1 \mathrm{VP}}$.

XYR1VP abolished cellulase production and increased xylanase production in $\mathrm{T}_{\mathrm{XYR} 1 \mathrm{VP}}$. By contrast, overexpression of xyr1 has been found not only to markedly enhance xylanase activity but also to increase cellulase activity in transformants (Mach-Aigner et al. 2008; Uzbas et al. 2012). Therefore, we hypothesized that the C-terminal fusion of XYR1 would alter the function of XYR1VP. Using COILS (Lupas et al. 1991; Lichius et al. 2015) predicted that the $C$ terminus of XYR 1 is a coiledcoil domain and likely mediates homodimerization of XYR1. Therefore, fusing the VP16 activation domain at the $\mathrm{C}$ terminus of XYR1 abrogated the expression of cellulase genes in $T$. reesei. It is very important to study the function of the $C$ terminus of XYR1. Nonetheless, the positive effect on xylanase gene expression observed after fusion of the VP16 activation domain indicated distinct regulatory mechanisms between cellulase and xylanase genes in terms of transcription. The different responsiveness of XYR1 to cellulase and xylanase was also observed by Pucher et al. (2011). Notably, the cellulolytic regulon of XYR1 is positively affected, whereas the xylanolytic regulon is affected negatively in a T. reesei QM9414 strain constitutively expressing xyr 1 (Pucher et al. 2011). These different regulatory mechanisms for cellulase gene transcription are supported by in silico identification of XYR1-binding sites in promoter regions, which are reported to occur at dramatically different frequencies in the promoter region of $c b h 1$ and xyn1: 14-fold for $c b h 1$ and only 4-fold for xyn1 (Rauscher et al. 2006; Furukawa et al. 2009).

\section{ACE2VP enhanced cellulase production}

The cellulase-related activities of ACE2VP transformant $\mathrm{T}_{\text {ACE2VP }}$ were detected to verify the effect of ACE2VP on cellulase production under Avicel and lactose culture conditions. $\mathrm{T}_{\mathrm{ACE} 2 \mathrm{VP}}$ had a significantly improved FPase activity (Fig. 4A), $p$ NPCase activity (Fig. 4B), and CMCase activity (Fig. 4C) in both Avicel- and lactosebased media. The highest FPase activity of $\mathrm{T}_{\mathrm{ACE} 2 \mathrm{VP}}$ was $2.7 \pm 0.2 \mathrm{U} / \mathrm{mL}$ in the Avicel-based medium on day 4; this effect was stronger by approximately $52 \%$ as compared to the control (Fig. 4A). In the lactose-based medium, FPase activity also increased by approximately $48 \%$ on day 4 as compared to the control (Fig. 4 A). Additionally, the amount of protein secreted from $\mathrm{T}_{\mathrm{ACE} 2 \mathrm{VP}}$ increased (Additional file 1: Figure S3a). Consistent with the improved cellulase production, the transcript levels of $c b h 1, c b h 2$, egl1, and egl2 in $\mathrm{T}_{\mathrm{ACE} 2 \mathrm{VP}}$ significantly increased by 2.0 - to 3.7 -fold in lactose- and Avicel-based media for 12 and $24 \mathrm{~h}$ subculturing (Fig. 4D, E). It has been reported that deleting ace 2 reduces total cellulase activity by $30-70 \%$ on cellulose (Aro et al. 2001). Because ACE2 was replaced by an ETA (ACE2VP), cellulase production was enhanced.

Nonetheless, there were no significant differences in the $p$ NPGase and xylanase activities between $\mathrm{T}_{\mathrm{ACE} 2 \mathrm{VP}}$ and control in either Avicel- or lactose-based media (Fig. 4D; Additional file 1: Figure S3b, c). Moreover, the transcript levels of $b g l 1, x y n 1$, and $x y n 2$ in $\mathrm{T}_{\mathrm{ACE} 2 \mathrm{VP}}$ showed no significant differences in the lactose- or Avicel-based medium as compared to the control (Fig. 4D, E; Additional file 1: Figure S3d, e). One study revealed no effect on xyn1 expression in strains in which ace 2 was deleted (Aro et al. 2001). It is possible that xylanase production was not improved in $\mathrm{T}_{\mathrm{ACE} 2 \mathrm{VP}}$ because ACE2 did not affect xyn 1 expression, as was the case for ACE2VP. ACE2 can affect the expression of xyn 2 and bgl1 (Aro et al. 2001; Stricker et al. 2008). Additionally, phosphorylation and dimerization are prerequisites for ACE2 to bind the promoters of target genes (Stricker et al. 2008). Fusion of the VP16 domain to the $C$ terminus of 

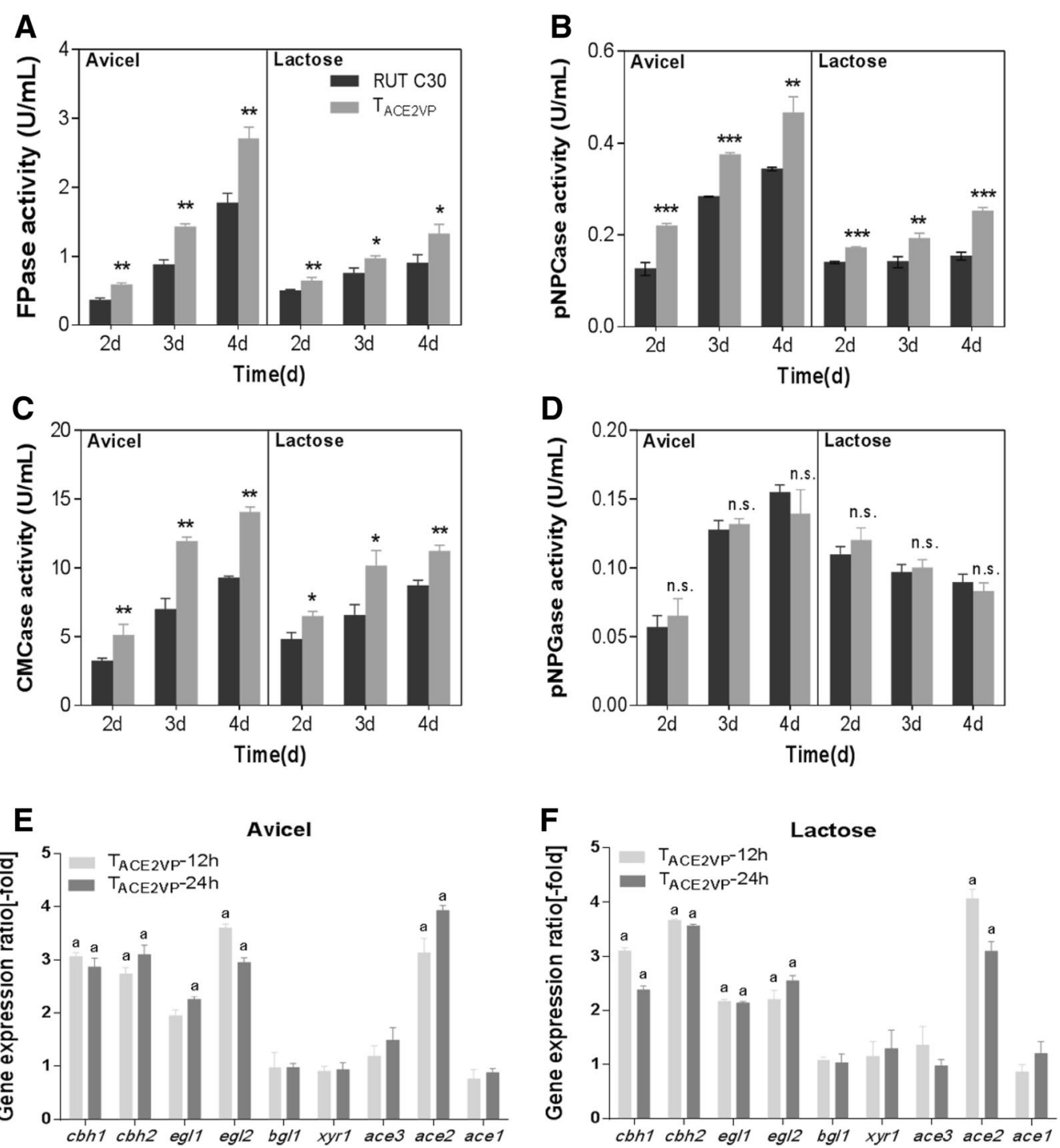

Fig. 4 Cellulase production and a comparison of transcript levels of cellulase-related genes between $T_{A C E 2 V P}$ and RUT C30. FPase (A), pNPCase (B), CMCase (C), and pNPGase (D) activities of RUT C30 and $T_{\text {ACE2VP }}$ after the switch from glycerol to $20 \mathrm{~g} / \mathrm{L}$ Avicel or lactose. Enzymatic activities were measured at 2, 3, and 4 days after the transfer. Error bars show the respective standard deviations of three biological replicates; asterisks indicate significant differences $\left({ }^{*} P \leq 0.05 ;{ }^{* *} P \leq 0.01 ;{ }^{* *} P \leq 0.001\right.$; n.s. not significant) between the transformants and RUT C 30 , as assessed by Student's $t$ test. Expression ratios of cellulase-related genes on $20 \mathrm{~g} / \mathrm{L}$ Avicel $(\mathbf{E})$ or lactose $(\mathbf{F})$ for 12 and $24 \mathrm{~h}$ after the switch from glycerol. Data on $\mathrm{T}_{\text {ACE2VP }}$ transformants were normalized to the corresponding gene expression at the same time points in RUT C30. Values represent the mean of three biological replicates, and error bars denote standard deviations. Gene expression ratios greater than twofold or less than 0.5-fold are marked with "a"

ACE2 may influence the native effects on $x y n 2$ and bgl1 expression.

We also analyzed the relative transcript levels of TFs $x y r 1$, ace3, ace 2 (ace $2 v p$ for $\mathrm{T}_{\mathrm{ACE} 2 \mathrm{VP}}$ ), and ace1 in $\mathrm{T}_{\mathrm{ACE} 2 \mathrm{VP}}$. The transcript level of ace2vp in $\mathrm{T}_{\mathrm{ACE} 2 \mathrm{VP}}$ was approximately 4.0-fold higher than that of ace2 in the control (Fig. 4D, E), indicating that the VP16 domain fused at the $\mathrm{C}$ terminus of ACE2 elevated its own transcript level. The increased transcript levels of ace $2 v p$ in $\mathrm{T}_{\mathrm{ACE} 2 \mathrm{VP}}$ may have also promoted cellulase production. The transcript levels of $x y r 1$, ace 3 , and ace1 in $\mathrm{T}_{\mathrm{ACE} 2 \mathrm{VP}}$ were similar to those in the control (an expression increase was approximately onefold), indicating that ACE2VP mainly affects the expression of cellulase genes and its own expression and has little effect on other TFs. 


\section{ACE1VP enhanced cellulase production}

To investigate the effect of ACE1VP on cellulase production, on the cellulase-related activities, and on the amount of protein secreted by ACE1VP transformants, $\mathrm{T}_{\mathrm{ACE1VP}}$ and RUT C30 were examined under Avicel and lactose culture conditions. The amount of protein secreted from $\mathrm{T}_{\text {ACE1VP }}$ notably increased (Additional file 1: Figure S4a). Additionally, elevated cellulase activities were observed in $\mathrm{T}_{\mathrm{ACE} \text { 1VP }}$ as compared to those in the control in both
Avicel- and lactose-based media (Fig. 5A-D). Cellulase production by $\mathrm{T}_{\mathrm{ACE1VP}}$ was higher in the Avicel-based medium than in the lactose-based medium. The highest FPase activity of $\mathrm{T}_{\text {ACE1VP }}$ transformants was $3.2 \pm 0.2 \mathrm{U} /$ $\mathrm{mL}$ in the Avicel-based medium, with an increase in activity of approximately $80 \%$ on day 4 compared to that in the control; this result is consistent with the enhanced $p$ NPCase, CMCase, and $p$ NPGase activities (Fig. 5B-D). Xylanase activities (on day 4) of $\mathrm{T}_{\mathrm{ACE} 1 \mathrm{VP}}$ transformants
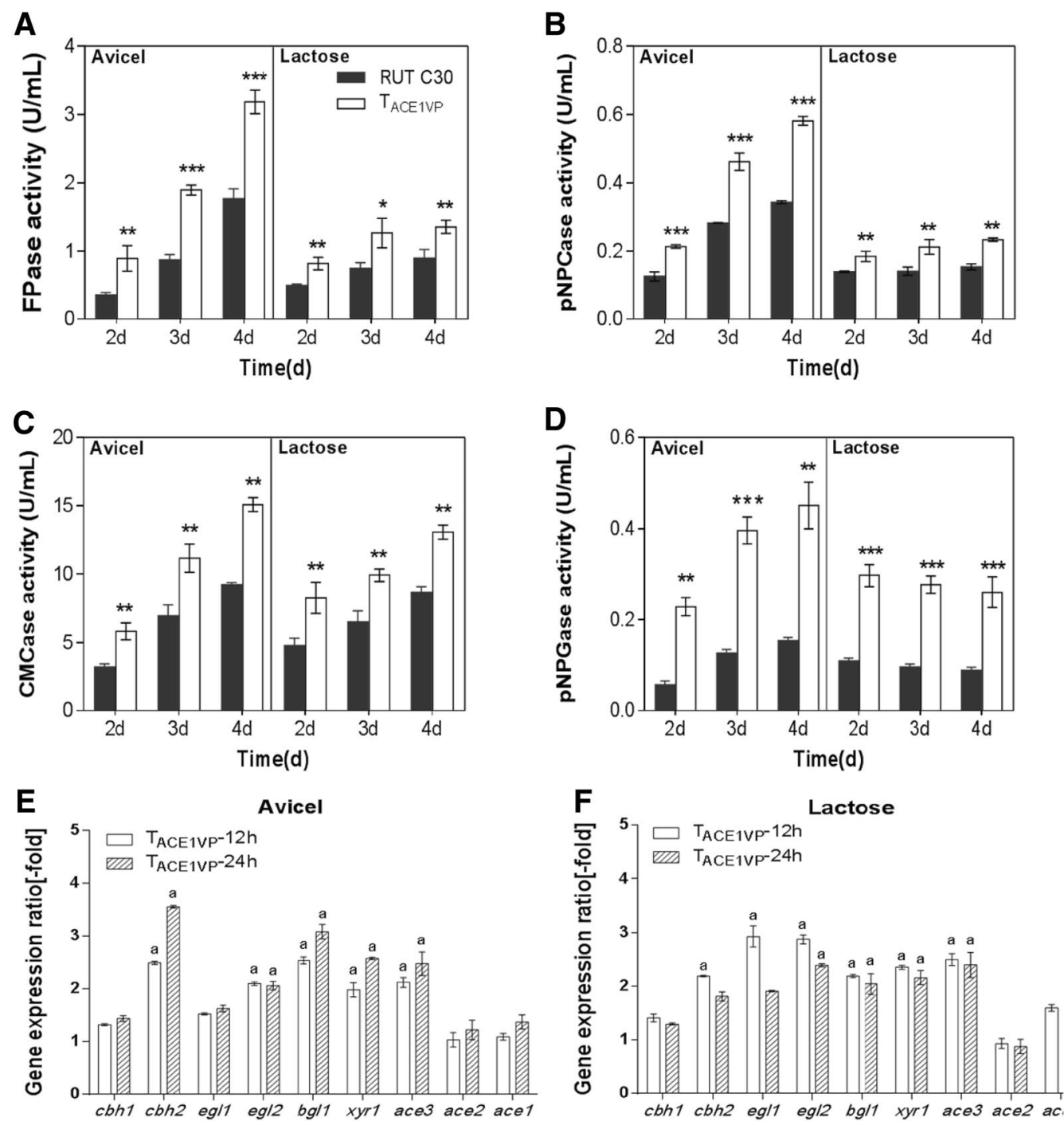

Fig. 5 Cellulase production and a comparison of transcript levels of cellulase-related genes between $T_{\text {ACE1 }}$ and RUT C30. FPase (A), pNPCase (B), CMCase (C), and pNPGase (D) activities of RUT C30 and T ACE1vP after the switch from glycerol to $20 \mathrm{~g} / \mathrm{L}$ Avicel or lactose. Enzymatic activities were measured at 2, 3, and 4 days after the transfer. Error bars show the respective standard deviations of three biological replicates; asterisks indicate significant differences $\left({ }^{*} P \leq 0.05 ;{ }^{* *} P \leq 0.01 ; * * * P \leq 0.001\right.$; n.s. not significant) between the transformants and RUT C30, as assessed by Student's $t$ test. Expression ratios of cellulase-related genes on $20 \mathrm{~g} / \mathrm{L}$ Avicel (E) or lactose (F) for 12 and $24 \mathrm{~h}$ after the switch from glycerol. The data on $T_{\text {XYRIVP }}$ transformants were normalized to the corresponding gene expression at the same time points in RUT C30. Values represent the mean of three biological replicates, and the error bars denote standard deviation. Gene expression ratios greater than twofold or less than 0.5 -fold are marked with "a" 
rose by nearly $50 \%$ in the Avicel-based medium as compared to the control (Additional file 1: Figure S4b, c). These results suggested that ACE1VP promotes cellulase and xylanase production in both Avicel- and lactosebased media. It has been reported that ace1 is a repressor and deleting ace 1 increases the amounts of cellulase produced in T. reesei (Aro et al. 2003). Here, ACE1VP is an artificial TF that promotes cellulase production. ACE1VP did not elevate the transcript level of itself but promoted the transcript levels of the cellulase genes and of transcriptional activators $x y r 1$ and ace3. Therefore, ACE1VP harbors positive transcriptional effects for cellulase production, whereas native ACE1 had a negative effect on cellulase production.

The transcript levels of cbh1, cbh2, egl1, egl2, bgl1, $x y n 1$, and xyn2 in $\mathrm{T}_{\mathrm{ACE} 1 \mathrm{VP}}$ increased 1.3- to 3.8 -fold in the Avicel-based medium as compared to the control for 12 and $24 \mathrm{~h}$ subculturing (Fig. 5E; Additional file 1: Figure S4d, e). Similarly, there was a remarkable increase $(\sim 1.3$ to 3.0-fold) in the transcript levels of cellulase genes in $\mathrm{T}_{\mathrm{ACE1VP}}$ as compared to the control strain in the lactosebased medium (Fig. 5F). The elevated transcript levels were consistent with increased enzyme production by $\mathrm{T}_{\mathrm{ACE1VP}}$ in both Avicel- and lactose-based media. Aro et al. (2003) reported that deleting ace1 increased the cbh1, cbh2, egl1, egl2, xyn1, and xyn2 transcription levels in the Avicel-based medium. Our results revealed that ACE1VP acts as a positive regulator improving cellulase and xylanase production in Avicel and lactose media.

The transcript levels of ace 2 and ace1 (ace1vp for $\mathrm{T}_{\text {ACE1VP }}$ ) in $\mathrm{T}_{\text {ACE1VP }}$ were similar to those in the control (the expression ratio was approximately onefold), whereas the transcript levels of $x y r 1$ and ace 3 in $\mathrm{T}_{\mathrm{ACE} 1 \mathrm{VP}}$ obviously increased in both Avicel-and lactose-based media as compared to the control (Fig. 5E, F). The xyr1 and ace 3 expression ratios were approximately 1.9- to 2.6fold in the Avicel- and lactose-based medium (Fig. 5E, F), indicating that the VP16 domain fused to the $\mathrm{C}$ terminus of ACE1 raised the transcript levels of key transcriptional activators XYR1 and ACE3. The increased transcript levels of xyr1 and ace 3 in $\mathrm{T}_{\mathrm{ACE} 1 \mathrm{VP}}$ reflect improved cellulase and xylanase production; this result is consistent with other reports of overexpression of $x y r 1$ and ace 3 in T. reesei (Mach-Aigner et al. 2008; Uzbas et al. 2012; Häkkinen et al. 2014).

\section{Hydrolysis of corn stover by cellulase from $\mathrm{T}_{\text {ACE1VP }}$ and $\mathrm{T}_{\mathrm{ACE} 2 \mathrm{VP}}$}

$\mathrm{T}_{\mathrm{ACE1VP}}$ and $\mathrm{T}_{\mathrm{ACE} 2 \mathrm{VP}}$ outperformed the control by showing markedly increased cellulase production. The crude cellulase produced by $\mathrm{T}_{\mathrm{ACE} 1 \mathrm{VP}}$ and $\mathrm{T}_{\mathrm{ACE} 2 \mathrm{VP}}$ was used to hydrolyze pretreated and biodetoxified corn stover (Qiu et al. 2017), with strain RUT C30 serving as a control. At

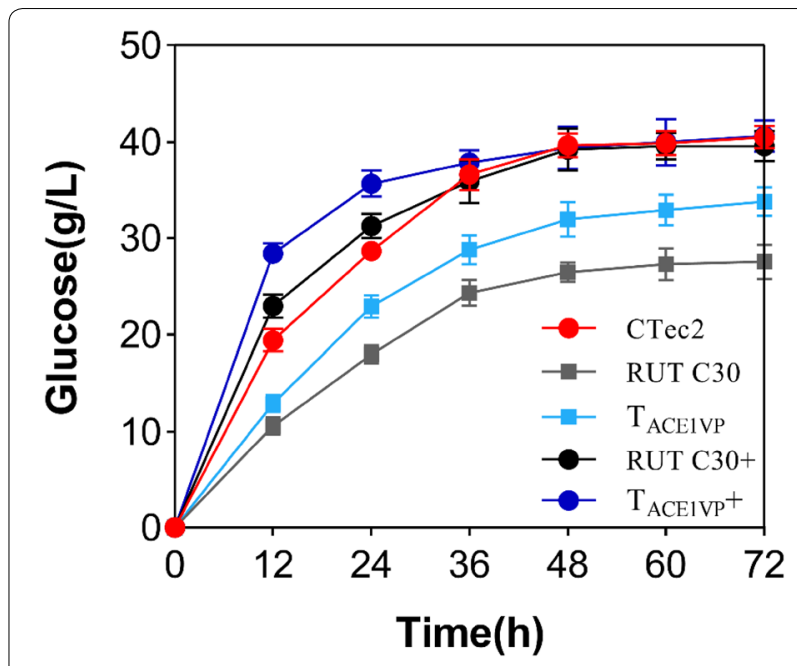

Fig. 6 Hydrolysis of corn stover by CTec2 and by the crude enzyme from $T_{\text {ACE1VP }}$ or RUT C30. The crude enzymes from $T_{\text {ACE1VP }}$ or RUT C30 were either supplemented with $\beta$-glucosidase (Sunson Enzymes) ( $T_{\text {ACE1VP }}+$, RUT C $30+$ ) or not supplemented with $\beta$-glucosidase ( $T_{\text {ACE1VP, }}, R U T$ C30) at the CBU/FPA ratio of 2. Commercial cellulase CTec2 (Novozymes, Bagsvaerd, Denmark) served as the control. Enzymatic hydrolysis was performed at $15 \mathrm{FPA} / \mathrm{g}$ pretreated corn stover). Values represent the mean and standard deviation of triplicate measurements

the same FPase loading (15 U/g pretreated corn stover), $33.8 \pm 1.5 \mathrm{~g} / \mathrm{L}$ glucose was produced after $72 \mathrm{~h}$ of incubation by crude cellulase from $\mathrm{T}_{\mathrm{ACE} 1 \mathrm{VP}}$. This result was approximately $22.6 \%$ higher than that produced by RUT C30 (Fig. 6). The increased glucose release resulted from enhanced $p$ NPGase activity in $\mathrm{T}_{\mathrm{ACE1VP}}$, which can hydrolyze cellobiose to glucose. There was no significant difference in the amount of glucose released between the crude enzymes from $\mathrm{T}_{\mathrm{ACE} V \mathrm{VP}}$ and the control (Additional file 1: Figure S5); these data are in agreement with the unimproved level of $p$ NPGase activity from $\mathrm{T}_{\mathrm{ACE} 2 \mathrm{VP}}$ in comparison with the control. Nonetheless, the production of cellulase by $\mathrm{T}_{\mathrm{ACE} 2 \mathrm{VP}}$ was improved, resulting in a smaller crude cellulase volume loading as compared to the control. Thus, the costs of cellulase from $\mathrm{T}_{\mathrm{ACE1VP}}$ to $\mathrm{T}_{\mathrm{ACE} 2 \mathrm{VP}}$ were reduced successfully.

After the supplementation with commercial $\beta$-glucosidase (4000 CBU/mL, Sunson Enzymes, Beijing, China) at the 2:1 CBU/FPA ratio, the glucose release from $\mathrm{T}_{\text {ACE1VP }}(40.6 \pm 1.6 \mathrm{~g} / \mathrm{L})$ and $\mathrm{T}_{\text {ACE2VP }}(39.4 \pm 2.1 \mathrm{~g} / \mathrm{L})$ was nearly the same as that observed with the commercial enzyme CTec2 $(40.5 \pm 1.2 \mathrm{~g} / \mathrm{L})$ (Fig. 6) at $72 \mathrm{~h}$, revealing that the enzymes produced by $\mathrm{T}_{\mathrm{ACE} 1 \mathrm{VP}}$ and $\mathrm{T}_{\mathrm{ACE2VP}}$ effectively hydrolyzed the pretreated corn stover. Additionally, cellulase from strain RUT C30 supplemented with $\beta$-glucosidase showed similar hydrolysis performance relative to the commercial $\mathrm{CTec} 2$. This phenomenon has 
been described in other reports too (Zhang et al. 2017, 2018), suggesting that the cellulase secreted by strain RUT C30 contains insufficient amounts of $\beta$-glucosidase (Pryor and Nahar 2015; Li et al. 2016; Zhang et al. 2016a). The $\mathrm{T}_{\text {ACE1VP }}$ strain showed higher $\beta$-glucosidase activity, which might be the reason for the improved hydrolysis yield with $\mathrm{T}_{\mathrm{ACE1VP}}$.

\section{Conclusion}

We designed a universal and simple pattern strategy for enhancing the transcriptional activation of native regulators ACE2, ACE1, and XYR1 from T. reesei by linking their $C$ terminus with the strong transcriptional activation domain of VP16. XYR1VP significantly improved xylanase gene transcription, while it abrogated cellulase gene expression. ACE2VP improved cellulase production in both lactose and Avicel media but was ineffective at inducing $p$ NPGase and xylanase production. Moreover, ACE1VP functioned as a positive regulator of cellulase and xylanase expression. This is the first study to report the effects of ETAs on cellulase and xylanase production; these data are helpful for strain improvement of $T$. reese $i$. Additionally, our universal and simple pattern strategy for constructing ETAs can serve as an alternative genetic engineering method for increasing the yield of industrial products in other hosts.

\section{Methods}

\section{Strains and media}

Hypercellulolytic strain T. reesei RUT C30 (ATCC 56765) serving as a parental strain and control was purchased from ATCC (Manassas, VA, USA). Escherichia coli DH5 $\alpha$ and Agrobacterium tumefaciens AGL-1 were used as host strains for recombinant DNA manipulations and for Agrobacterium-mediated transformation (Michielse et al. 2008). DH5 $\alpha$ and AGL-1 cells were cultured in the LuriaBertani medium.

\section{Construction of ETAs and their expression plasmids}

Three ETAs-XYR1VP, ACE2VP, and ACE1VP-were designed by fusing the VP16 domain to the $\mathrm{C}$ terminus of XYR1, ACE2, or ACE1, respectively (Fig. 1). The C-terminal coding sequences and downstream sequences of natural TFs (ACE2, ACE1, and XYR1) were employed as the left ( $\left.5^{\prime}-\right)$ and right $\left(3^{\prime}-\right)$ homologous arms, respectively (Fig. 1). The linker and activation domain of VP16 of the herpes simplex virus protein were amplified by PCR from pG1V (Wang et al. 2014). All the primers are listed in Table S1 (Additional file 1). An unmarked genetic modification tool LML2.1 (Zhang et al. 2016b) served as the skeleton of all the plasmids, in which the hygromycin resistance gene was removed by xylose-induced Cre recombinase. The amplified $5^{\prime}$ - and $3^{\prime}$-fragments were fused to the corresponding sites $\mathrm{PacI} / \mathrm{Xba \textrm {I }}$ and $\mathrm{SwaI}$ of LML2.1, respectively, with the Seamless Cloning and Assembly Kit (TransGen, Beijing, China). The resulting vectors were named as pXYR1VP, pACE1VP, and pACE2VP (Fig. 1).

\section{Transformation of $T$. reesei and verification of the transformed clones}

Agrobacterium-mediated transformation (Michielse et al. 2008), transformed-clone verification, and xyloseinduced marker rescue (Zhang et al. 2016b) were performed to obtain the ETA-transformed strains $\mathrm{T}_{\mathrm{XYR} 1 \mathrm{VP}}$, $\mathrm{T}_{\text {ACE1VP, }}$, and $\mathrm{T}_{\text {ACE2VP. }}$. Single-copy DNA integration in the transformed clones was verified by diagnostic PCR, amplicon sequencing, and quantitative PCR (qPCR) as described by Li et al. (2017). The related primers are presented in Additional file 1: Figure S1 and Table S1. TransStart TipTop Green qPCR SuperMix (TransGen) was used for qPCR assays. For each ETA, three randomly selected transformants $\left(\mathrm{T}_{\mathrm{XYR} 1 \mathrm{VP}}-1 /-2 /-3\right.$, $\mathrm{T}_{\mathrm{ACE} 2 \mathrm{VP}}-1 /-2 /-3$, and $\left.\mathrm{T}_{\mathrm{ACE} 1 \mathrm{VP}}-1 /-2 /-3\right)$ were collected.

\section{The biomass concentration assay}

For the fungal growth assay, conidia (final concentration $10^{6} / \mathrm{mL}$ ) from each T. reesei strain were inoculated into $100 \mathrm{~mL}$ of the minimal medium [MM, $\left(\mathrm{NH}_{4}\right)_{2} \mathrm{SO}_{4} 5 \mathrm{~g} / \mathrm{L}$; Urea $0.3 \mathrm{~g} / \mathrm{L} ; \mathrm{KH}_{2} \mathrm{PO}_{4} 15 \mathrm{~g} / \mathrm{L} ; \mathrm{CaCl}_{2} 0.6 \mathrm{~g} / \mathrm{L} ; \mathrm{MgSO}_{4}$ $0.6 \mathrm{~g} / \mathrm{L} ; \mathrm{FeSO}_{4} \cdot 7 \mathrm{H}_{2} \mathrm{O} 5 \mathrm{mg} / \mathrm{L} ; \mathrm{ZnSO}_{4} \cdot 7 \mathrm{H}_{2} \mathrm{O} 1.4 \mathrm{mg} / \mathrm{L}$; $\mathrm{CoCl}_{2} \cdot 6 \mathrm{H}_{2} \mathrm{O} 2 \mathrm{mg} / \mathrm{L} ; \mathrm{pH} 5.5$ ] containing $20 \mathrm{~g} / \mathrm{L}$ glycerol, lactose, or Avicel in $500 \mathrm{~mL}$ Erlenmeyer flasks and were cultivated by shaking $(200 \mathrm{rpm})$ at $28{ }^{\circ} \mathrm{C}$ for $72 \mathrm{~h}$. Two milliliters of the culture liquid was collected every $12 \mathrm{~h}$ for biomass concentration analysis as described by Bischof et al. (2013). Intracellular protein contents were measured by means of the Modified Lowry Protein Assay Kit (Sangon Biotech, Shanghai, China). The biomass (in dry weight per liter) was quantified by calculating the intracellular protein content in a glycerol-, Avicel-, or lactose-based medium assuming $0.32 \mathrm{~g}$ of intracellular protein per gram of dry biomass (Bischof et al. 2013).

\section{Enzyme production in a flask}

For the cellulase production assay, conidia $\left(10^{7} / \mathrm{mL}\right)$ from each T. reesei strain were inoculated into $100 \mathrm{~mL}$ of the Mandels Andreotti (MA) medium (Mandels and Andreotti 1978) supplemented with $1 \mathrm{~g} / \mathrm{L}$ peptone (Oxoid, Basingstoke, England) and $20 \mathrm{~g} / \mathrm{L}$ glycerol in $500 \mathrm{~mL}$ Erlenmeyer flasks and were cultivated by shaking (200 rpm) at $28^{\circ} \mathrm{C}$ for 2 days. Pregrown mycelia were harvested by filtration, washed with distilled water, and dried with sterile filter paper. Equal amounts of these mycelia were transferred into two $50 \mathrm{~mL}$ aliquots of fresh MA supplemented with $1 \mathrm{~g} / \mathrm{L}$ peptone with $20 \mathrm{~g} / \mathrm{L}$ 
lactose, or Avicel as the sole carbon source (Chen et al. 2016). Incubation was continued at $28{ }^{\circ} \mathrm{C}$ with shaking at $200 \mathrm{rpm}$ for 4 days. When enzyme production was analyzed in glycerol, the mycelial culture time was prolonged to 4 days without transfer. Two milliliters of the culture liquid was collected via centrifugation at $14,000 \times g$ and $4{ }^{\circ} \mathrm{C}$ for $10 \mathrm{~min}$. The culture supernatants were subjected to cellulase activity measurements. The mycelia were washed with distilled water, dried with sterile filter paper, and subjected to RNA extraction and biomass concentration assays.

\section{RNA extraction and Real-time quantitative PCR (RT-qPCR) analysis}

RNA was extracted using the FastRNA Pro Red Kit (MP Biomedicals, Santa Ana, CA, USA). cDNA was synthesized with TransScript All-in-One First-Strand cDNA Synthesis SuperMix for qPCR (TransGen). The levels of gene-specific mRNA were assessed by RT-qPCR on an ABI StepOne Plus thermocycler (Applied Biosystems, Foster City, CA, USA). The primers are described in Additional file 1: Table S1. The cycling conditions comprised $30 \mathrm{~s}$ initial denaturation and polymerase activation at $95{ }^{\circ} \mathrm{C}$, followed by 40 cycles of $5 \mathrm{~s}$ at $95{ }^{\circ} \mathrm{C}$ and $60 \mathrm{~s}$ at $64{ }^{\circ} \mathrm{C}$. Threshold cycle $(\mathrm{Ct})$ values and PCR efficiency rates were used to calculate relative expression quantities by the ABI software. Transcript levels of target genes were normalized to sar1 expression (Steiger et al. 2010) by the $2^{-\Delta \Delta \mathrm{Ct}}$ method.

\section{Enzymatic activity and the protein concentration assay}

Produced cellulase activities against filter paper (FP), $p$-nitrophenyl-D-cellobioside ( $p$ NPC), sodium salt of carboxymethyl cellulose (CMC), and 4-nitrophenyl-betaD-galactopyranoside ( $p$ NPG) were measured at $\mathrm{pH} 5.0$ throughout cultivation. One unit of FPase or CMCase activity forms $1 \mu \mathrm{mol}$ of reducing sugar per minute during the hydrolysis reaction, which was quantified by the 3,5-dinitrosalicylic acid method with glucose as a standard (Miller 1959). One unit of $p$ NPCase or $p$ NPGase activity was defined as the amount of the enzyme needed to produce $1 \mu \mathrm{mol}$ of $p$-nitrophenol per minute during the hydrolysis reaction. Xylanase I and xylanase II activities were measured by xylan degradation at $\mathrm{pH} 3.7$ and 5.0, respectively, as described by Stricker et al. (2008). One unit of xylanase activity was defined as the amount of the enzyme needed to generate $1 \mu \mathrm{mol}$ of xylose reducing sugar equivalents per minute under the defined assay conditions. Protein concentration was determined by means of the Modified Lowry Protein Assay Kit (Sangon Biotech, Shanghai, China).

\section{Enzymatic hydrolysis of pretreated corn stover}

Pretreated and biodetoxified corn stover was found to contain $37.6 \%$ of cellulose and $4.4 \%$ of hemicellulose by dry mass and was kindly provided by Professor Jie Bao (Qiu et al. 2017). The crude enzymes produced by the $T$. reesei ETA transformants and RUT C30 were collected in the Avicel-based MA medium after 4 days of fermentation after the switch from the glycerin-based medium. Saccharification was performed on $10 \%(\mathrm{w} / \mathrm{v})$ pretreated corn stover as a substrate in a flask with FPase loading (15 U/g dry biomass) at $50^{\circ} \mathrm{C}$ and pH $5.0(50 \mathrm{mM}$ sodium citrate buffer) for $72 \mathrm{~h}$. The enzymes were supplemented with $\beta$-glucosidase (Sunson Enzymes) at the CBU/FPA ratio of two to hydrolyze pretreated corn stover when necessary. The glucose release was evaluated as described by Li et al. (2016).

\section{Statistical analysis}

All the experiments were conducted with three biological replicates and three technical replicates for each biological replicate. Student's two-tailed $t$ test was performed in Microsoft Excel (Office 2013) (Microsoft, Redmond, WA, USA) to detect significant differences between two samples. $P \leq 0.05$ was considered to indicate statistical significance.

\section{Additional file}

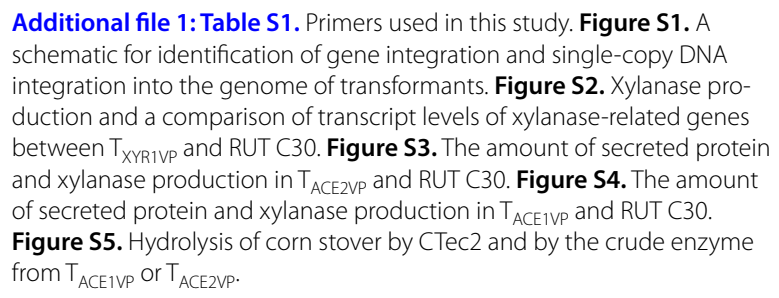

\section{Abbreviations}

ETA: enhanced transcriptional activator; TF: transcription factor; aa: amino acid residues; FPA or FPase: filter paper activity; $p$ NPCase: $p$-nitrophenol-D-cellobioside hydrolase activity; CMCase: sodium salt of carboxymethyl cellulose hydrolase activity; $p N P G$ ase: 4-nitrophenyl-beta-D-galactopyranoside hydrolase activity; pNPC: -nitrophenyl-D-cellobioside; pNPG: 4-nitrophenyl-beta-D-galactopyranoside; CMC: sodium salt of carboxymethyl cellulose; U: international units; CBU: cellobiase units; RT-qPCR: real-time quantitative polymerase chain reaction; MA medium: Mandels Andreotti medium; MM: minimal medium.

\section{Authors' contributions}

WW ${ }^{1}$ initiated, designed, and coordinated the study and reviewed the manuscript. JZ planned and carried out the experiments and measurements and interpreted the experimental data. CW analyzed the partial data. DW and $W W^{2}$ provided the research funding. All authors read and approved the final manuscript. 


\section{Author details}

${ }^{1}$ New World Institute of Biotechnology, State Key Lab of Bioreactor Engineering, East China University of Science and Technology, P.O.B. 311, 130 Meilong Road, Shanghai 200237, China. ${ }^{2}$ State Key Lab of Bioreactor Engineering, East China University of Science and Technology, Shanghai 200237, China.

\section{Acknowledgements}

We wish to thank Prof. Jie Bao (State Key Lab of Bioreactor Engineering, East China University of Science and Technology, Shanghai, China) for providing the pretreated and biodetoxified corn stover.

\section{Competing interests}

The authors declare that they have no competing interests.

\section{Availability of data and materials}

All the data generated or analyzed during this study are included in this article.

\section{Consent for publication}

All the coauthors have read and approved the submission to Bioresources and Bioprocessing.

\section{Ethics approval and consent to participate}

Not applicable.

\section{Funding}

This research was supported by the National Natural Science Foundation of China (No. C010302-31500066) and the Fundamental Research Funds for the Central Universities (No. 222201714053).

\section{Publisher's Note}

Springer Nature remains neutral with regard to jurisdictional claims in published maps and institutional affiliations.

Received: 9 June 2018 Accepted: 14 August 2018

Published online: 18 August 2018

\section{References}

Akel E, Metz B, Seiboth B, Kubicek CP (2009) Molecular regulation of arabinan and $\mathrm{L}$-arabinose metabolism in Hypocrea jecorina (Trichoderma reesei). Eukaryot Cell 8:1837-1844

Aro N, Saloheimo A, Ilmén M, Penttilä M (2001) ACEll, a novel transcriptional activator involved in regulation of cellulase and xylanase genes of Trichoderma reesei. J Biol Chem 276(26):24309-24314

Aro N, Ilmén M, Saloheimo A, Penttilä M (2003) ACEl of Trichoderma reesei is a repressor of cellulase and xylanase expression. Appl Environ Microb 69(1):56-65

Biddy MJ, Davis R, Humbird D, Tao L, Dowe N, Guarnieri MT, Linger JG, Karp EM, Salvachúa D, Vardon DR, Beckham GT (2016) The techno-economic basis for coproduct manufacturing to enable hydrocarbon fuel production from lignocellulosic biomass. ACS Sustain Chem Eng. 4:3196-3211

Bischof RH, Fourtis L, Limbeck A, Gamauf C, Seiboth B, Kubicek CP (2013) Comparative analysis of the Trichoderma reesei transcriptome during growth on the cellulase inducing substrates wheat straw and lactose. Biotechnol Biofuels 6(1):127

Bischof RH, Ramoni J, Seiboth B (2016) Cellulases and beyond: the first 70 years of the enzyme producer Trichoderma reesei. Microb Cell Fact 15(1):106

Buchert J, Oksanen J, Pere J, Siika-aho M, Suurnäkki A, Viikari L (1998) Application of Trichoderma reesei enzymes in the pulp and paper industry. In: Harman GE, Kubicek CP (eds) Trichoderma and Gliocladium. Taylor and Francis Ltd, London, pp 343-364

Chen L, Zou G, Wang J, Wang J, Liu R, Jiang Y, Zhao G, Zhou Z (2016) Characterization of the $\mathrm{Ca}^{2+}$ responsive signaling pathway in regulating the expression and secretion of cellulases in Trichoderma reesei Rut-C30. Mol Microbiol 100(3):560-575

Dos Santos Castro L, de Paula RG, Antonieto AC, Persinoti GF, Silva-Rocha R, Silva RN (2016) Understanding the role of the master regulator XYR1 in Trichoderma reesei by global transcriptional analysis. Front Microbiol 7:175
Furukawa T, Shida Y, Kitagami N, Mori K, Kato M, Kobayashi T, Okada H, Ogasawara W, Morikawa Y (2009) Identification of specific binding sites for XYR1, a transcriptional activator of cellulolytic and xylanolytic genes in Trichoderma reesei. Fungal Genet Biol 46:564-574

Hahn-Hagerdal B, Galbe M, Gorwa-Grauslund MF, Liden G, Zacchi G (2006) Bio-ethanol-the fuel of tomorrow from the residues of today. Trends Biotechnol 24:549-556

Häkkinen M, Valkonen MJ, Westerholm-Parvinen A, Aro N, Arvas M, Vitikainen M, Penttilä M, Saloheimo M, Pakula TM (2014) Screening of candidate regulators for cellulase and hemicellulase production in trichoderma reesei and identification of a factor essential for cellulase production. Biotechnol Biofuels 7(1):14

Ju YL, Sung BH, Yu BJ, Lee JH, Sang HL, Mi SK, Koob MD, Sun CK (2008) Phenotypic engineering by reprogramming gene transcription using novel artificial transcription factors in Escherichia coli. Nucleic Acids Res 36(16):e102

Lee SW, Kim E, Kim JS, Oh MK (2013) Artificial transcription regulator as a tool for improvement of cellular property in Saccharomyces cerevisiae. Chem Eng Sci 103:42-49

Li Y, Liu C, Bai F, Zhao X (2016) Overproduction of cellulase by Trichoderma reesei RUT C30 through batch-feeding of synthesized low-cost sugar mixture. Bioresour Technol 216:503-510

Li C, Lin F, Zhou L, Qin L, Li B, Zhou Z, Jin M, Chen Z (2017) Cellulase hyperproduction by Trichoderma reesei mutant SEU-7 on lactose. Biotechnol Biofuels 10:228

Lichius A, Bidard F, Buchholz F, Le Crom S, Martin J, Schackwitz W, Austerlitz T, Grigoriev IV, Baker SE, Margeot A, Seiboth B, Kubicek CP (2015) Genome sequencing of the Trichoderma reesei QM9136 mutant identifies a truncation of the transcriptional regulator XYR1 as the cause for its cellulasenegative phenotype. BMC Genomics 16:326

Lupas A, Dyke MV, Stock J (1991) Predicting coiled coils from protein sequences. Science 252:1162-1164

Mach-Aigner AR, Pucher ME, Steiger MG, Bauer GE, Preis SJ, Mach RL (2008) Transcriptional regulation of $x y r 1$, encoding the main regulator of the xylanolytic and cellulolytic enzyme system in Hypocrea jecorina. Appl Environ Microbiol 74:6554-6562

Mandels M, Andreotti RE (1978) Problems and challenges in the cellulose to cellulase fermentation. Process Biochem 13:6-13

Martinez D, Berka RM, Henrissat B, Saloheimo M, Arvas M, Baker SE, Chapman J, Chertkov O, Coutinho PM, Cullen D (2008) Genome sequencing and analysis of the biomass-degrading fungus Trichoderma reesei (syn. Hypocrea jecorina). Nat Biotechnol 26(5):553

Michielse CB, Hooykaas PJ, Ca VDH, Ram AF (2008) Agrobacterium-mediated transformation of the filamentous fungus Aspergillus awamori. Nat Protoc 3(10):1671-1678

Miller L (1959) Use of dinitrosalicylic acid reagent for determination of reducing sugar. Anal Chem 31:426-428

Parisutham V, Kim TH, Lee SK (2014) Feasibilities of consolidated bioprocessing microbes: from pretreatment to biofuel production. Bioresour Technol 161:431-440

Portnoy T, Margeot A, Seidl-Seiboth V, Le CS, Ben CF, Linke R, Seiboth B, Kubicek CP (2011) Differential regulation of the cellulase transcription factors XYR1, ACE2, and ACE1 in Trichoderma reesei strains producing high and low levels of cellulase. Eukaryot Cell 10(2):262-271

Pryor SW, Nahar N (2015) $\beta$-Glucosidase supplementation during biomass hydrolysis: how low can we go? Biomass Bioenergy 80:298-302

Pucher ME, Steiger MG, Mach RL, Mach-Aigner AR (2011) A modified expression of the major hydrolase activator in Hypocrea jecorina (Trichoderma reesei) changes enzymatic catalysis of biopolymer degradation. Catal Today 167:122-128

Qiu Z, Gao Q, Bao J (2017) Constructing xylose-assimilating pathways in Pediococcus acidilactici for high titer D-lactic acid fermentation from corn stoverfeedstock. Bioresour Technol 245:1369-1376

Rauscher R, Wurleitner E, Wacenovsky C, Aro N, Stricker AR, Zeilinger S, Kubicek CP, Penttila M, Mach RL (2006) Transcriptional regulation of xyn1, encoding xylanase I, in Hypocrea jecorina. Eukaryot Cell 5:447-456

Sadowski I, Ma J, Triezenberg S, Ptashne M (1988) GAL4-VP16 is an unusually potent transcriptional activator. Nature 335(6190):563-564

Saloheimo A, Aro N, IImén M, Penttilä M (2000) Isolation of the acel gene encoding a Cys2-His2 transcription factor involved in regulation of 
activity of the cellulase promoter cbh1 of Trichoderma reesei. J Biol Chem 275:5817-5825

Steiger MG, Mach RL, Mach-Aigner AR (2010) A Stricker $n$ accurate normalization strategy for RT-qPCR in Hypocrea jecorina (Trichoderma reesei). J Biotechnol 145:30-37

Stricker AR, Grosstessner-Hain K, Wurleitner E, Mach RL (2006) Xyr1 (xylanase regulator 1 ) regulates both the hydrolytic enzyme system and $\mathrm{D}$-xylose metabolism in Hypocrea jecorina. Eukaryot Cell 5:2128-2137

Stricker AR, Trefflinger P, Aro N, Penttilä M, Mach RL (2008) Role of ace2 (activator of cellulases 2) within the xyn2 transcriptosome of Hypocrea jecorina. Fungal Genet Biol 45(4):436

Su X, Chu X, Dong Z (2009) Identification of elevated transcripts in a Trichoderma reesei strain expressing a chimeric transcription activator using suppression subtractive hybridization. World J Microb Biotechnol 25(6):1075-1084

Triezenberg SJ, Kingsbury RC, Mcknight SL (1988) Functional dissection of VP16, the trans-activator of herpes simplex virus immediate early gene expression. Genes Dev 2(6):718-729

Uzbas F, Sezerman U, Hartl L, Kubicek CP, Seiboth B (2012) A homologous production system for Trichoderma reesei secreted proteins in a cellulase-free background. Appl Microbiol Biotechnol 93:1601-1608

Vicari KJ, Vicari KJ, Shatova T, Joo KK, Scarlata CJ, Humbird D, Wolfrum EJ, Beckham GT (2012) Uncertainty in techno-economic estimates of cellulosic ethanol production due to experimental measurement uncertainty Biotechnol Biofuels 5(1):1-12

Wang W, Shi X, Wei D (2014) Light-mediated control of gene expression in filamentous fungus Trichoderma reesei. J Microbiol Methods 103:37-39

Zeilinger S, Mach RL, Schindler M, Herzog P, Kubicek CP (1996) Different inducibility of expression of the two xylanase genes xyn 1 and $x y n 2$ in Trichoderma reesei. J Biol Chem 271:25624-25629

Zhang F, Bai F, Zhao X (2016a) Enhanced cellulase production from Trichoderma reesei RUT C30 by engineering with an artificial zinc finger protein library. Biotechnol J 11:1282-1290

Zhang L, Zhao X, Zhang G, Zhang J, Wang X, Zhang S, Wang W, Wei D (2016b) Light-inducible genetic engineering and control of non-homologous end-joining in industrial eukaryotic microorganisms: LML 3.0 and OFN 1.0. Sci Rep 6:20761

Zhang X, Li Y, Zhao X, Bai F (2017) Constitutive cellulase production from glucose using the recombinant Trichoderma reesei strain overexpressing an artificial transcription activator. Bioresour Technol 223:317-322

Zhang J, Zhang G, Wang W, Wang W, Wei D (2018) Enhanced cellulase production in Trichoderma reesei RUT C30 via constitution of minimal transcriptional activators. Microb Cell Fact 17:75

\section{Submit your manuscript to a SpringerOpen ${ }^{\odot}$ journal and benefit from:}

- Convenient online submission

- Rigorous peer review

- Open access: articles freely available online

- High visibility within the field

- Retaining the copyright to your article

Submit your next manuscript at $\boldsymbol{\nabla}$ springeropen.com 